\title{
La etnicidad en el espacio público Los descendientes de inmigrantes polacos en la Provincia de Misiones
}

\section{Katarzyna Porada}

\author{
Consejo Nacional de Investigaciones Científicas y Técnicas, CONICET, Argentina \\ Correo electrónico: katarzynaporada@gmail.com
}

Recibido:

2 de diciembre de 2017 Aceptado:

13 de agosto de 2018

\section{Resumen}

Los esfuerzos por consolidar una imagen simbólica de Argentina como país plural, tanto a nivel étnico-cultural como religioso, se han visto reflejados en los últimos años en la aparición de diversos festivales, desfiles o ferias, en los que las colectividades de origen inmigrante ocupan un lugar protagónico. Estos proyectos de visibilización de la diversidad étnica han consistido en resaltar aquellos aspectos de las respectivas culturas de origen que pueden ser identificados con cierta facilidad, no ofrecen dificultades a la hora de ser interpretados y permiten ser apreciados por aquellos que no pertenezcan al grupo. En el presente artículo, centrándonos en la comunidad polaca de la provincia de Misiones, nos proponemos analizar cómo las nuevas iniciativas y la exposición de ciertos elementos de la cultura y las tradiciones polacas ante los espectadores extracomunitarios han marcado la forma y el contenido de los elementos que se exhiben. Al mismo tiempo, analizaremos cómo influye el contexto en el que está inserto el grupo en la forma de expresar su pertenencia étnica y en qué medida ha determinado los cambios y transformaciones experimentadas por ciertos marcadores étnicos.

\section{Ethnicity in the public space. The descendants of Polish im- migrants in the Misiones Province}

\begin{abstract}
The efforts to consolidate a symbolic image of Argentina as a plural country, at ethnic-cultural and religious level, have been reflected recently in the appearance of various festivals, parades or fairs, in which the leading role is occupied by the collectivities of immigrant origin. The main characteristics of projects that make visible the ethnic diversity in the public space have consisted in highlighting those aspects of the respective cultures, which can be identified
\end{abstract}

\section{Palabras clave}

Polacos; Provincia de Misiones; Descendientes de Inmigrantes; Etnicidad; Festivales

\section{Key words}

Poles; Misiones province; Immigration; Descendants; Ethnicity; Festivals 
easily, do not offer interpretative difficulties and can be appreciated by those who do not belong to the group. In the present article, focusing on the Polish Community in the Misiones province, we propose to analyze how the new initiatives and the exposure of some elements of Polish culture and traditions to non-community spectators have marked the form and content of the elements that are exhibited. At the same time, we will analyze how the context in which the group is inserted influences the way in which they express their ethnic belonging and how it has determined the changes and transformations experienced by certain ethnic markers.

\section{Etnia no espaço público. Os descendentes de imigrantes po- loneses na província de Misiones}

\section{Resumo}

Palavras-chave

Poloneses; Provincia de Misiones; Descendentes de imigrantes; Etnicidade; Festivais de imigrantes
Os esforços para consolidar uma imagem simbólica da Argentina como um país plural, tanto a nível étnico-cultural como religioso, têm-se reflectido nos últimos anos no surgimento de vários festivais, desfiles ou feiras, em que as comunidades de origem imigrante ocupam um lugar de destaque. Estes projectos para tornar visível a diversidade étnica consistiram em destacar os aspectos das respectivas culturas de origem que podem ser facilmente identificados, não oferecem dificuldades de interpretação e podem ser apreciados por aqueles que não pertencem ao grupo. Neste artigo, centrado na comunidade polaca na província de Misiones, propomos analisar como as novas iniciativas e a exposição de certos elementos da cultura e tradições polacas aos telespectadores não comunitários marcaram a forma e o conteúdo dos elementos em exposição. Ao mesmo tempo, analisaremos como o contexto em que o grupo está inserido influencia a forma como expressa a sua pertença étnica e a medida em que determinou as mudanças e transformações vividas por certos marcadores étnicos.

La comunidad polaca radicada en la región de Misiones es resultado de los movimientos migratorios iniciados en la última década del siglo XIX y finalizados con el estallido de la Segunda Guerra mundial. Durante décadas, el nordeste argentino ha sido uno de los más activos y numerosos centros polacos en el continente latinoamericano. Han pasado ya casi setenta años desde que prácticamente se detuvieron los procesos migratorios entre ambos países. En la actualidad, algunos de los descendientes de los colonos polacos siguen preservando la vinculación con el país de origen. Como cabe esperar, el contenido cultural que conservan no se ha mantenido de forma invariable e inmune al contacto con la sociedad mayoritaria y con los demás grupos étnicos. Tampoco ha estado al margen del contexto en el que está inserta la comunidad. Por el contrario, los aspectos que hoy en día los integrantes de la colectividad consideran como representativos de las tradiciones de sus antepasados son muy diferentes de aquellos empleados por los propios inmigrantes en épocas anteriores. Es por ello que en el presente artículo, una vez esbozada la especificidad de los movimientos migratorios entre ambos países, nos centraremos en analizar las particularidades de la vinculación con el país de origen que conserva la actual comunidad polaca. Al mismo tiempo, estudiaremos cómo 
influye el contexto en el que está inserto el grupo -principalmente la reciente visibilización de la diversidad étnica en el espacio público-, en la forma de expresar su pertenencia étnica y en qué medida ha determinado los cambios y transformaciones experimentadas por ciertos marcadores étnicos.

\section{Los polacos en la provincia de Misiones}

El inicio de la migración a gran escala hacia el nordeste argentino data desde la última década del siglo XIX. En el año 1897, en Buenos Aires, desembarcaron 14 familias polaco-ucranianas, procedentes de la región de Galitzia. Su llegada al puerto bonaerense no fue planeada y se debió al hecho de que les había sido denegado el permiso de viaje hacia los Estados Unidos, principal lugar de destino para la emigración polaca en el periodo anterior a la Primera Guerra Mundial (Brożek, 1984). Al parecer, los polacos no cumplían con los requisitos impuestos por la política inmigratoria estadounidense; algunos carecían de la documentación obligatoria; mientras que otros presentaban los primeros síntomas de tuberculosis. Después de haber sido rechazados por la comisión sanitaria, aceptaron viajar a Argentina, país que no imponía tantas restricciones como Estados Unidos. Tras su arribo a Buenos Aires, se dirigieron a Michał Szelągowski, inmigrante polaco radicado en Argentina desde 1878. Szelągowski, asumiendo el papel de intermediario, se puso en contacto con el gobernador de Misiones, Juan José Lanusse.

En la correspondencia mantenida entre ambos, el gobernador aseguraba: “Escribirle hoy y anticiparle que estos inmigrantes estarán bien venidos. Tengo intérprete. Sírvase decirme cuántos son y asegúreles todo mi mejor concurso. Creo háceles Ud. un buen servicio mandándoles aquí". ${ }^{1}$ La ayuda que J. J. Lanusse estaba dispuesto a brindar a las familias galitzianas no era desinteresada y se debía, principalmente, a la necesidad de garantizar la integridad territorial de la región fronteriza, con muy escasa densidad poblacional y carente de grandes núcleos urbanos (Stemplowski, 2011). Según el Censo Nacional de 1895, más de la mitad de la población de Misiones -que apenas alcanzaba los 33 mil habitantes- había nacido fuera del territorio nacional; la mayoría de ellos eran originarios de Brasil y Paraguay (De la Fuente, et al., 1898).

La emigración rural desde las tierras polacas hacia Argentina se inscribe dentro de un proceso migratorio transoceánico a gran escala, iniciado en la segunda mitad del siglo XIX desde una Polonia dividida entre grandes potencias vecinas: Rusia, Imperio austrohúngaro y Prusia. La escasez de tierra y la precaria situación que se vivía en el campo constituyeron los principales motivos que forzaron a miles de personas a emigrar en busca de un sustento económico. En forma paralela, a los que tomaron la decisión de establecerse en la provincia de Misiones se les ofrecían considerables facilidades a la hora de adquirir grandes parcelas de tierra. En consecuencia, la llegada de las primeras familias al nordeste argentino -inicialmente a la ciudad de Apóstoles- dio origen al establecimiento de fuertes cadenas migratorias. En la primera etapa, los polacos se fueron radicando en Azara, San José, Corpus; y posteriormente, en Cerro Corá, Bonpland, Gobernador Roca, Posadas, Oberá o en Campo Viera. En poco tiempo, a los colonos que venían directamente de Polonia, se sumaron aquellos que provenían del sur de Brasil. Se calcula que antes del estallido de la Primera Guerra mundial, a Misiones se dirigieron aproximadamente 6 mil polacos (Stemplowski, 2011, p. 132). El estallido de la guerra paralizó temporalmente los movimientos migratorios entre ambos países.
1. Carta manuscrita del 12 de julio de 1897 del Gobernador J. J. Lanusse dirigida a Michał Szel gowski (Fondos del Archivo de la Biblioteca Polaca Ignacio Domeyko en Buenos Aires). 
2. El año 1945, además de marcar el fin del conflicto bélico, trajo unos cambios importantes en la escena internacional y dividió al mundo en dos bloques antagónicos. Como resultado, Polonia quedó situada detrás de "la cortina de hierro" y pasó a formar parte de la zona controlada por la URSS. Se calcula que, en la segunda posguerra, ingresaron a la Argentina alrededor de 19 mil polacos. La mayoría de ellos fueron soldados desmovilizados y sus familias que al finalizar la guerra se encontraban fuera de las fronteras nacionales y tomaron la decisión de no retornar a la Polonia Popular. Casi todos se fueron estableciendo en grandes urbes, principalmente en Buenos Aires. 3. La presente investigación se basa en las entrevistas semiestructuradas realizadas a cincuenta personas residentes en la provincia de Misiones (Apóstoles, Oberá,

Posadas y colonia Wanda) durante el trabajo de campo que se llevó a cabo en abril del año 2012 y en mayo de 2013, de un mes de duración cada una. Fueron entre-

vistados veinticinco hijos, dieciséis nietos y nueve bisnietos de inmigrantes polacos. Las entrevistas

realizadas fueron complementadas con la observación participante (Guber, 2001) que se aplicó a lo largo del trabajo de campo. Esta consistió en la participación directa en diversos eventos o actos desarrollados por los descendientes de inmigrantes polacos de la provincia de Misiones, entre los que podríamos mencionar: participación en los ensayos de conjuntos de danza y en las clases de idioma; asistencia a las actividades de carácter cultural y religioso; organización y asistencia a las fiestas conmemorativas o festivales étnicos. Al mismo tiempo, la autora asistió a

las reuniones y eventos de carácter privado con familiares y amigos de las personas entrevistadas.
El fin del conflicto bélico en 1918 significó para Polonia la recuperación de la independencia. A pesar del júbilo inicial, ya en los primeros meses resultó evidente que el país pasaba por una gran inestabilidad política, económica y social, acompañada por una alta desocupación. En estas circunstancias, el gobierno polaco empezó a promover la emigración, percibida como una forma de aliviar las tensiones internas del país y atenuar el problema del desempleo. Al comienzo de los años veinte, EEUU seguía siendo el principal país receptor de movimientos migratorios originados en tierras polacas. No obstante, en 1924, la promulgada Ley de Orígenes Nacionales -conocida como la "ley de cuotas"- limitó la inmigración de ciudadanos polacos hasta los seis mil ingresos anuales (Brożek, 1984). Las restricciones de la política migratoria estadounidense se reflejaron en una importante reorientación de los movimientos migratorios polacos, y Argentina se convirtió en uno de los principales países receptores. En las dos décadas que separan las guerras mundiales, a este país latinoamericano inmigraron 160 mil ciudadanos polacos (Smolana, 1983; Mazurek, 2006), de los cuales aproximadamente 5 mil se dirigieron a la provincia de Misiones (Stemplowski, 2011).

El creciente número de inmigrantes y sus hijos -incluidos los de origen polaco- reveló la necesidad de colonizar las tierras al norte de la región. En consecuencia, la demanda abrió paso a las compañías privadas de origen europeo, que, tras haber adquirido grandes territorios en la zona, comenzaron a revender las parcelas a los colonos particulares (Kraustolf, 2011). Este fue el caso de la empresa colonizadora de origen polaco creada en Posadas en 1931 y bautizada con el nombre de "Sociedad Vístula". La entidad adquirió 1500 hectáreas de tierra en las proximidades del Puerto Naranjito, a orillas del río Paraná, donde se fundó, en el año 1932, la colonia Polana. Durante la primera mitad de 1930, se establecieron allí 40 familias polacas (Mazurek, 2006). En 1935, la Compañía Colonizadora del Norte S. A., otra empresa con capital polacoargentino, compró aproximadamente 60 mil hectáreas en la zona norte del Alto Paraná (Kraustolf, 2011). Un año más tarde, en los territorios adquiridos, se fundó la colonia Wanda; y en 1937, a casi 40 kilómetros de distancia, la colonia Gobernador Lanusse. En ambas localidades se establecieron alrededor de 600 personas (Stemplowski, 2011). Los proyectos de la Compañía Colonizadora del Norte SA estaban enfocados a una escala mucho mayor; no obstante, el estallido de la Segunda Guerra mundial interrumpió los movimientos poblacionales entre ambos países e imposibilitó seguir con los planes colonizadores. Como resultado, se calcula que antes de 1939 en Misiones residían aproximadamente 50 mil inmigrantes polacos y sus descendientes (Bryszewska, et al., 2004). Una vez concluido el conflicto bélico, la migración polaca hacia Misiones fue prácticamente nula. ${ }^{2}$

El tiempo transcurrido desde que se detuvo el proceso migratorio entre ambos países provocó un inevitable cambio intergeneracional entre los que pertenecen a la comunidad polaca. Las personas nacidas en Polonia constituyen un porcentaje cada vez más reducido dentro del grupo, el cual está conformado por una mayoría de descendientes. Se trata de un grupo de personas de diferentes edades, sexos y niveles educacionales, una parte sustancial de las cuales nació en familias interétnicas. En la actualidad, algunos de ellos siguen perpetuando lo que a sus ojos constituye la cultura y tradiciones del país de sus antepasados. ${ }^{3}$ Durante las décadas que nos separan desde la llegada del último grupo migratorio, los marcadores étnicos han sido condicionados y moldeados por circunstancias específicas. Por lo tanto, y para entender mejor la particularidad de la etnicidad que preserva la actual comunidad polaca en Misiones, es obligatorio detenernos en las circunstancias que la rodean. 


\section{De las tendencias asimilacionistas a la visibilización de la diversidad étnica}

Desde la segunda mitad del siglo XIX y durante gran parte del siglo XX, las migraciones internacionales han ocupado un lugar importante en los proyectos políticos del Estado argentino. Ante el creciente número de extranjeros residentes en el país -que en 1914 habían superado un 30\% del total de la población (Martínez, 1916)-, los sucesivos gobiernos demostraron una preocupación por asegurar la "unidad nacional" e inculcar los referentes comunes a las masas de diverso origen. Las tendencias asimilacionistas quedaron reflejadas, por ejemplo, en la imposición de la obligatoriedad de la educación laica y gratuita en el idioma castellano y en la introducción del servicio militar obligatorio (Quijada, 1992). Ambos elementos se convirtieron en las principales herramientas para garantizar la homogeneidad de la población y promover una instrucción patriótica de acuerdo con el "espíritu tradicional" argentino (Devoto, 2009). En consecuencia, el papel del Estado argentino y sus agencias fue el de una "máquina de aplanar diferencias" de extrema e insuperable eficacia (Segato, 2007, p. 58).

Tras un largo proceso de "desetnicización" de los grupos de origen inmigrante, las fuertes tendencias unificadoras presentes en los proyectos oficiales han sido sustituidas, en las últimas décadas, por los esfuerzos de consolidar una imagen simbólica de Argentina como un país plural, cuyo atributo fundamental es la heterogeneidad étnico-cultural y religiosa (Irazuzta, 2001b, p. 40). Una de las maneras de fomentar dicha imagen se ha basado en la escenificación de una determinada faceta de esta pluralidad étnica. Las celebraciones organizadas por los organismos estatales, tanto a nivel nacional como provincial o municipal, han pretendido reforzar el discurso sobre la diversidad a través de exhibiciones folklorizadas de las particularidades culturales de las distintas comunidades (Fischman, 2013). De ahí -en los últimos años con un considerable apoyo de las autoridades- empezaron a multiplicarse diversos festivales, desfiles o ferias, en los que las diferentes expresiones del folklorismo ${ }^{4}$ presentadas por las respectivas colectividades de origen inmigrante ocupan un lugar protagónico. Si bien dichos eventos no constituyen una novedad en el contexto argentino, la escala que han alcanzado, el respaldo oficial con el que cuentan, así como la cobertura mediática que reciben, han influido en su carácter y dimensiones. En otras palabras, la prolongada invisibilidad de la "diversidad" ha sido sustituida, recientemente, por una creciente hipervisibilización de las diferencias (Grimson, 2006).

Este fenómeno también se ha registrado en la provincia de Misiones. Entre los actos que resaltan la diversidad étnica de la provincia, el de mayor envergadura es, sin duda, la "Fiesta del Inmigrante", celebrada anualmente en el mes de septiembre en la ciudad de Oberá. Según la versión oficial que mantienen las colectividades participantes, los orígenes de la fiesta se remontan a la década del ochenta, cuando varias familias de distintas procedencias incluidas las polacas- decidieron reunirse para celebrar conjuntamente el "Día del Inmigrante". Con el tiempo, el evento fue ganando mayor repercusión, y en 1992 la celebración superó su carácter provincial, para convertirse en la "Fiesta Nacional del Inmigrante". Dada su creciente popularidad y la afluencia de espectadores, el evento fue trasladado al Parque de las Naciones, un espacioso predio destinado para tal fin, ubicado a las afueras de la ciudad. Allí, las colectividades construyeron pintorescos edificios que representan la arquitectura tradicional de los respectivos países participantes.
4. Siguiendo a Josep Martí, por folklorismo entendemos una interpretación, más o menos estilizada, de determinados aspectos de la cultura popular, que implica una selección subjetiva de aquellos elementos del folklore que son considerados como los más interesantes o atractivos para el público potencial (Marti, 1996, 1999). 
5. La información pertenece a la página oficial de la Fiesta Nacional del Inmigrante: http:// www.fiestadelinmigrante.com.ar/
Actualmente, la fiesta tiene una duración de diez días, aunque los actos y actividades de diversa índole que la acompañan se extienden más allá de las fechas establecidas. Como podemos leer en la página oficial: "todo el mes de septiembre, Oberá se vestirá de Inmigrantes para el asombro de los visitantes, que junto con los anfitriones compartirán momentos inolvidables" ${ }^{5}$ En el acto inaugural, un desfile por la avenida principal de la ciudad da inicio a innumerables eventos culturales o deportivos. Dentro de la amplia oferta recreativa se encuentran también numerosos concursos, exhibiciones de grupos de danza pertenecientes a las respectivas colectividades, así como las muy concurridas "Elecciones de la Reina Nacional del Inmigrante". Al mismo tiempo, la fiesta ofrece la posibilidad de asistir a varios conciertos y espectáculos, protagonizados por cantantes de moda, invitados especialmente al evento con el objetivo de asegurar la asistencia de espectadores. A las actividades programadas, se suman degustaciones de platos y bebidas "típicas" que las colectividades ofrecen en sus sedes.

Además de esta celebración multitudinaria, la provincia de Misiones también acoge celebraciones a menor escala. Este, por ejemplo, es el caso del Festival de las Colectividades "Así canta el Corazón de Misiones", organizado en el mes de noviembre en la localidad de Dos de Mayo, el "Festival Provincial del Colono" en Dos Arroyos y, la "Fiesta de la Navidad del Colono" en Alba Posse, ambos actos celebrados en diciembre; o el "Encuentro Interprovincial de Folklore", con sede en el Puerto Esperanza, donde junto con el folklore nacional, presentan sus actuaciones los grupos folklóricos de diferentes colectividades de origen inmigrante.

A los eventos en los que numerosas colectividades comparten espacio para homenajear la figura del inmigrante, se suman aquellos organizados exclusivamente por la comunidad polaca. Este es el caso del "Día del Colono Polaco", celebrado anualmente el día 8 de junio. Los actos que se llevan a cabo en esta fecha conmemoran la llegada de las primeras familias polacas a la Argentina y su posterior establecimiento en Misiones. También en esta ocasión, se destacan las presentaciones de bailes y trajes típicos, así como la degustación de diversos platos tradicionales. Al igual que las celebraciones anteriormente descritas, los festejos están abiertos al público y cuentan con el apoyo de las autoridades locales.

Por último, reviste un especial interés el caso de la colonia Wanda; localidad, como ya hemos señalado, fundada en 1936 por inmigrantes procedentes de Polonia. Por esta razón, no es casualidad que el evento que conmemora la fundación de Wanda, celebrado anualmente en el mes de agosto, esté relacionado con la figura del colono polaco. Si bien dichas celebraciones tienen una trayectoria más larga, al igual que las mencionadas anteriormente, siguen las tendencias visibles en toda la provincia y se han ido transformando de manera considerable en los últimos años. El punto central de los actos conmemorativos lo constituye la elección de la reina. Durante el concurso de belleza, entre las participantes adultas se elige a Miss Wanda, y entre las más pequeñas, a Miss Wandita. Paralelamente, se organiza el festival folclórico "Noche de las Colectividades", al que acuden numerosos conjuntos folklóricos de la zona. El ambiente festivo de las celebraciones provocó que el aniversario de la fundación de Wanda se haya convertido, recientemente, en una de las fiestas más populares y concurridas de la zona.

Independientemente del lugar de celebración o del origen de las comunidades participantes, el contenido y la forma de los eventos señalados resultan muy 
parecidos. Todos son presentados como "rituales de confraternidad", en los que los colectivos participantes comparten pacíficamente el mismo espacio. Las celebraciones presentan una amplia oferta de actividades, para que las familias locales o los turistas puedan pasar una tarde agradable y disfrutar de esta particular manifestación cultural que, en palabras de Ignacio Irazusta, se convierte en una performance sobre la identidad (Irazuzta, 2001a). La imagen de diversidad igualitaria, exenta de actitudes discriminatorias, queda demostrada también en la distribución simbólica de los lugares donde se organizan los eventos. En el caso de los actos compartidos por varias comunidades, a todos los participantes se les ceden espacios iguales o semejantes; por ejemplo, un escenario común o puestos de las mismas características, destinados a la exhibición de los productos étnicos (Fischman, 2011).

Asimismo, para promocionar la imagen de los armoniosos encuentros multiculturales como libres de cualquier tipo de tensión y con el objetivo de asegurar la afluencia del público, estos cuentan con una importante cobertura mediática. En las fechas próximas a la inauguración, los actos que están por celebrarse se promueven con frecuencia en las noticias de la radio, en la televisión y en la prensa locales. Paralelamente, varios de estos eventos cuentan con sus propias páginas web o disponen de perfiles en redes sociales, donde sistemáticamente se publican fotos y vídeos de las actividades realizadas.

Además de promocionar la imagen de Argentina como una nación plural, la divulgación que reciben los actos señalados revela otro objetivo que acompaña su organización. Nos referimos al uso del patrimonio cultural de los grupos de origen inmigrante, como un poderoso recurso económico y como una de las estrategias para promover el turismo (Kremer, 2013). La organización de las actividades en el espacio público y su carácter festivo permiten dinamizar la actividad mercantil de varios sectores de la zona (Parma, 2013). Los organizadores, la localidad auspiciante, las colectividades participantes y la población local se convierten en beneficiarios de las iniciativas mencionadas (Medina, 2003, p. 836). En consecuencia, la instauración de nuevos espacios y formas de presentar la pertenencia étnica -así como el impacto que dichas actividades tienen sobre la sociedad y los espectadores concurrentes- han influido de manera significativa en la conformación de la etnicidad que presenta la actual comunidad polaca.

\section{Etnicidad simbólica}

El extendido empleo, en las últimas décadas, de los términos etnia, etnicidad y grupo étnico, ha creado una falsa percepción de que existe un consenso sobre sus contenidos (Bazurco Osorio, 2006). No obstante, las principales líneas teóricas desde las que se han pretendido abordar los fenómenos étnicos -la primordialista, la constructivista y la instrumentalista- contradicen esa idea (Guber, 1995). Aunque las diferentes líneas interpretativas han elaborado las propuestas percibidas a menudo como contradictorias, en el presente trabajo hemos optado por el uso simultáneo de determinados aspectos pertenecientes a las perspectivas señaladas, ya que se ha considerado que, antes que irreconciliables, resultan complementarios en el análisis propuesto.

De esta forma, tal como señalan los constructivistas, se ha partido del supuesto que la etnicidad es un fenómeno dinámico y flexible, y que sus características dependen del contexto en el que está inserto un determinado grupo (Barth, 1976). Asimismo, y de acuerdo con el enfoque instrumentalista, la adscripción 
a una comunidad dada puede servir -y de hecho, frecuentemente sirve- para satisfacer determinados fines $\mathrm{y}$, por tanto, debe responder a las necesidades e intereses de los individuos que forman parte de ella. En consecuencia, sus formas culturales frecuentemente son manejadas, e incluso manipuladas, para defender dichos intereses (Cohen, 1981). Por otro lado, el sentido de pertenencia y la vinculación entre los miembros de una comunidad, pese a su dinamismo, encuentra su legitimación en la percepción de un pasado y un origen compartido (Monkevicius, 2010); es decir, la naturaleza misma del grupo se basa en una visión primordialista de la identidad étnica que desarrollan sus integrantes, en una vinculación -percibida como "natural"- que los sujetos sienten tener hacia los integrantes de su propia comunidad (Geertz, 1992).

Al mismo tiempo, los grupos étnicos, según Barth, son categorías de adscripción e identificación utilizadas para organizar la interacción entre los individuos (Barth, 1976). Dicha interacción se refleja en los procesos de inclusión y de exclusión, que vienen marcados por las fronteras étnicas que establece cada grupo. Dichas fronteras étnicas, si bien permiten definir quiénes pertenecen al grupo y quiénes quedan excluidos, no son construcciones fijas e inamovibles. Por el contrario, dependen del contexto en el que está ubicado un determinado colectivo. En otras palabras, se trata de "un recipiente organizacional capaz de recibir diversas proporciones y formas de contenido en los diferentes sistemas socioculturales" (Barth, 1979, p. 16). Por lo tanto, un mismo grupo de individuos que considera ser portador de valores y marcadores étnicos compartidos, al estar ubicado en contextos diferentes, se vería obligado a adoptar distintas formas de conducta y patrones de existencia. De ahí, en el caso de las comunidades ya asentadas, los aspectos culturales que son percibidos como propios no son una reproducción exacta de la cultura ni de las tradiciones de los inmigrantes. Por el contrario, se trata de elementos que han estado sometidos a procesos de adaptación al contexto circundante y, frecuentemente, también a los de reinvención (Gil, 2007).

Según afirma Herbert Gans, los descendientes de inmigrantes tienden a acudir a aquellos símbolos y determinados aspectos de la cultura de origen que son visibles, que pueden ser reconocidos con facilidad y que, paralelamente, contienen una alta carga emotiva (Gans, 1979). Como resultado, se trata de un proceso de selección de aquellos aspectos culturales que sean atractivos para los integrantes del grupo y de la eliminación de los que no lo son (Waters, 1990). En consecuencia, el sistema cultural que conservan los descendientes de inmigrantes queda reducido a un determinado número de marcadores étnicos, sin que se tengan en cuenta los demás elementos que forman parte de la cultura de origen (Alba, 1990). Esta elección de símbolos predilectos no se realiza en un vacío, y depende, en gran medida, de las circunstancias en las que está inserto el grupo. De ahí, el reciente fenómeno de la escenificación de la diversidad étnica y la exposición ante el público extracomunitario del contenido perteneciente con anterioridad a la esfera exclusivamente comunitaria (Bialogorski, 2011) ha marcado una gran huella en la etnicidad de los descendientes de inmigrantes polacos en la provincia de Misiones.

La principal característica de los nuevos proyectos de visibilización de la diversidad étnica en el ámbito público consiste en resaltar aquellos aspectos que no ofrecen dificultades a la hora de ser interpretados, y permiten ser apreciados por personas que no pertenecen al grupo. Es decir, se autorizan y legitiman ciertas representaciones de las diferencias, mientras que otras no tienen cabida dentro de las iniciativas recientes. En este contexto, como señala Segato, la etnicidad se reduce al papel de repertorio de emblemas cada vez 
menos densa en contenidos que podríamos denominar culturales, y cada vez más enfática en los aspectos icónicos y estereotípicos de la tradición (Segato, 2007). En otras palabras, el contenido presentado se caracteriza por exhibir los elementos más despolitizados de la cultura de origen de los respectivos grupos étnicos (Irazuzta, 2001b). De ahí, las danzas y cantos populares, la vestimenta tradicional, junto con la oferta culinaria, ocupan un lugar privilegiado en todos los actos y actividades desarrolladas por la comunidad, y su atractivo resulta, a menudo, mucho mayor que cualquier otro aspecto de la cultura de origen. Es por ello, que la participación en el conjunto de baile, el hecho de vestir en ciertas ocasiones el traje típico o acudir a uno de los eventos mencionados constituye, para los descendientes de inmigrantes, una vía predilecta de expresar públicamente su pertenencia étnica. En estas palabras lo describen los participantes de la Fiesta Nacional del Inmigrante de Oberá:

\begin{abstract}
Nosotros como ballet hacemos las danzas típicas en el escenario mayor (...). Además, estamos con nuestros trajes típicos, recorriendo el parque... Todo lo hacemos porque nos gusta, porque realmente queremos sentirnos bien. Es una forma de representar nuestros ancestros, de mantener esta cultura que fue traída por nuestros abuelos... (hombre, Oberá, 29 años, bisabuela materna polaca).

En la Fiesta del Inmigrante nosotros tratamos de mostrar toda nuestra cultura. En el desfile inaugural, nosotros desfilamos con un montón de polaquitos y polaquitas, chiquitos, grandes, viejos, los que no somos tan viejos, pero todavía tenemos ganas... $Y$ con orgullo. Yo me siento así, y cuando uno me dice, che, ¿te vas a disfrazar este año? No, yo no me voy a disfrazar, yo me voy a vestir de polaco. Y cuando la vez pasada en el desfile agarré ese mástil con la bandera y la hice flamear, eso es lo que nos mueve a nosotros... Es lindo pertenecer a una colectividad (hombre, Oberá, 67 años, padre polaco).
\end{abstract}

Por otro lado, en el caso de que varias comunidades compartan el mismo espacio, el espectáculo que se ofrece debe marcar claramente las diferencias entre ellas y así evitar que se confunda lo "típico" de una colectividad con lo "auténtico" de la otra (Handler, 1986). De ahí, las nuevas modalidades de interacción entre diferentes grupos influyen en la construcción y las particularidades que adquieren las fronteras étnicas (Barth, 1979). En este sentido, una rica variedad de trajes regionales y el extremo cuidado de los detalles en la vestimenta pasan a ser el principal elemento diferenciador del grupo y constituyen de los símbolos más destacados, a través del cual los descendientes de inmigrantes manifiestan su pertenencia étnica. En consecuencia, además que convertirse en eficaces canalizadores de los sentimientos etnicitarios (Martí, 1999), dichos elementos cumplen una función de potentes marcadores de la identidad étnica. Lo refleja el siguiente testimonio:

Todas las regiones tienen un traje totalmente diferente, que tiene su significado muy meticuloso en todos los detalles... que por allí otras colectividades no lo tienen. Y veo la colectividad alemana y veo que ellos tienen sus trajes bien sencillos, sin ningún detalle. En cambio nosotros tenemos bordados, flores, cintas, que es algo bien autóctono de la colectividad... (mujer, 23 años, abuela materna y abuela paterna polacas, Wanda, Misiones).

Las personas entrevistadas parecen ignorar el hecho de que sus antepasados inmigrantes, con toda seguridad, no otorgaban el mismo valor a los elementos mencionados, e incluso podemos afirmar que estos fueron desconocidos para ellos. Esto se debe, por un lado, a la forma claramente estilizada que adquiere, en la actualidad, la expresión basada en la cultura popular y, por el 
otro, porque las coreografías que se presentan tienden a incluir, dentro de la misma exhibición artística, elementos procedentes de zonas geográficamente muy dispersas (Kantor, 1990).

Una función parecida la desempeña la comida. Los distintos platos considerados típicos actúan como un potente marcador étnico y se convierten en otro elemento fundamental de la expresión de la etnicidad al que los descendientes de inmigrantes polacos acuden durante diferentes festivales, ferias y encuentros para afirmar su origen y diferenciarse de los demás. El ambiente celebratorio y la finalidad de entretener a los espectadores determinan la elección de los elementos que se exhiben (Porada, 2016). Como señala Pizarro, los mecanismos de folklorización seleccionan, aíslan y descontextualizan rasgos culturales esencializados para satisfacer la demanda de quienes asisten a los eventos (Pizarro, 2013). Es por ello que, en el contexto de la escenificación, la comida y las bebidas tradicionales, junto con la presentación de trajes regionales y la exhibición de danzas populares, se constituyen en uno de los principales reductos donde se localiza la "garantía de autenticidad" de un determinado grupo (Irazuzta, 2001b). En otras palabras, la puesta en escena de la etnicidad contribuye a elegir $\mathrm{y}$, posteriormente, a resignificar determinados aspectos considerados sobresalientes de la cultura polaca. Estos son elevados al rango de símbolos privilegiados del grupo en el imaginario colectivo (TrebuniaStaszel, 2014).

\section{Resignificación de prioridades}

Una clara predilección por determinados elementos de la cultura no es el único cambio experimentado por la comunidad polaca en Misiones. El número y la escala de las actividades dedicadas a homenajear a la figura del inmigrante, el apoyo oficial que reciben, así como el interés que despiertan entre el público extracomunitario, han tenido un gran impacto dentro de la colectividad y han afectado la agenda de las respectivas asociaciones. En particular llama la atención que, en relativamente poco tiempo, los actos promovidos desde fuera de la comunidad han logrado convertirse en fundamentales a los ojos de los descendientes de inmigrantes, para expresar su pertenencia étnica y mantener la vinculación con el país de sus antepasados. En ocasiones, incluso, han pasado a ser el eje central en torno al cual giran todas las actividades comunitarias a lo largo del año. En estos términos, una integrante de la colectividad polaca en Oberá relata el impacto que tiene entre los integrantes del grupo su participación en la Fiesta Nacional del Inmigrante:

La Fiesta es un gran atractivo de la provincia, te diría (...) pero también nos jugó en contra a la hora de estar en contacto con lo que es la cultura, porque a veces nos encasillamos tanto en lo que es la fiesta... Y bueno, hay que cocinar para la fiesta, que hay que juntar plata para la Fiesta, hay que bailar para la fiesta y se perdió un poco el hilo de esa cuestión, que por allí sí tienen las otras asociaciones (mujer, Oberá, 27 años, bisabuelos maternos polacos).

Entre los motivos que justifican la participación en los eventos promovidos desde fuera de la comunidad, un lugar protagónico lo ocupa el deseo de "rendir homenaje" a los familiares que hace décadas llegaron a la Argentina. Al respecto, el hecho de asistir a las fiestas auspiciadas por las autoridades argentinas es percibido -tanto por los dirigentes colectivos como por los integrantes de la colectividad-como una oportunidad de perpetuar el legado cultural: "Y realmente vivimos la Fiesta porque sentimos nuestra ascendencia, nosotros 
somos descendientes y la 'Fiesta del Inmigrante' es una forma de rendir homenaje a todos nuestros antepasados" (hombre, Oberá, 67 años, padre polaco).

La particularidad de los eventos desarrollados ha implicado también ciertos cambios en la conformación del colectivo. En la actualidad, para poder participar en los eventos destinados al público, resulta imprescindible poseer un conjunto de baile. Estos han asumido el papel de "la cara visible" de los respectivos grupos y se han convertido en uno de los requisitos para ser invitados a representar la cultura y las tradiciones de los antepasados. Así lo explica la profesora del conjunto de la colonia Wanda:

\begin{abstract}
Sí, ahora estamos por ir a El Dorado y cuando estaba la otra profesora fueron a Oberá, fueron a Buenos Aires. Y acá, bueno, viste, hay otros dos pueblitos, también siempre nos invitan, siempre para fiestas. Generalmente se hacen muchas fiestas en las colectividades o así y siempre nos invitan a participar... Un día fuimos a participar, había como un congreso internacional en el polideportivo y llegamos después de la misa con esos trajes, íbamos a bailar y salíamos y la gente sorprendida. Venía de México, no sé de dónde y nos sacaban fotos y nos sacaban fotos, fuimos centro de atención. Eran gente de otros lados... (mujer, colonia Wanda, 36 años, abuelos maternos polacos).
\end{abstract}

La importancia reciente que los grupos de bailes folklóricos han adquirido dentro de las respectivas colectividades lo demuestran también las fechas de su creación. Salvo el caso de Apóstoles, hasta hace poco las colectividades no han sentido la necesidad de mantener los conjuntos de danzas tradicionales. El grupo “Nasza Mała Polska" ("Nuestra Pequeña Polonia"), perteneciente a la Colectividad Polaca en Oberá, empezó a funcionar en 2003. El grupo de danzas "Wieczysław Kowalewski" de la colonia Wanda fue fundado en el año 2004. En el caso de Posadas, tras una serie de intentos, en 2010 fueron retomadas las iniciativas para constituir una sección de danzas juveniles que, hasta la fecha, funciona de manera discontinua. En el mencionado caso de Apóstoles, si bien el conjunto "Nasz Balet" ("Nuestro Ballet") fue fundado ya en la década de los sesenta, con el transcurrir de los años perdió atractivo y dejó de existir. No obstante, los cambios recientes han incentivado a los integrantes de la colectividad a retomar las actividades en 2004.

\title{
Cambios y modificaciones de la etnicidad
}

La puesta en escena de los distintos elementos de la etnicidad -anteriormente reservados exclusivamente a la esfera comunitaria- se ha reflejado en una serie de cambios, transformaciones e incluso reinvenciones. Eso se debe, principalmente, al hecho de que los proyectos enfocados a resaltar la diversidad étnica en el ámbito público suponen la presencia de espectadores que vienen a apreciar y a consumir los "productos étnicos", pero que, en ocasiones, no han tenido contacto con la cultura y las tradiciones que se exhiben. Por lo tanto, el contenido que se presenta tiene que adecuarse tanto a su capacidad interpretativa como a sus gustos, al tiempo que requiere de una necesaria simplificación (Martí, 1999). En consecuencia, durante los actos, que supuestamente pretenden dar a conocer al público extracomunitario las particularidades de una determinada cultura, aquellos elementos cuyo significado podría resultarles incomprensible a los espectadores quedan eliminados (Waters, 1990). Este, por ejemplo, es el caso de la lengua étnica. Según se ha podido comprobar, los cantos que tradicionalmente acompañaban las danzas polacas quedan excluidos del evento. 
Por otro lado, la escenificación de la etnicidad conlleva, a menudo, los esfuerzos por resaltar determinados rasgos, incluidos los fenotípicos, que supuestamente responden a la imagen de cómo son los representantes de un determinado grupo étnico. Es decir, en el contexto analizado, no es suficiente que los propios actores se perciban a sí mismos como distintos de otros grupos; también tienen que ser reconocidos como tales por el público asistente (Giménez, 1997). De ahí, el contenido expuesto viene marcado por una constante preocupación por adecuarse a las expectativas externas. Dicho de otra forma, las exhibiciones presentadas bajo el lema de la cultura "auténtica" (Handler, 1986) están condicionadas por la percepción que los demás tienen de la colectividad polaca y por lo que el público espera ver durante el evento. Lo demuestra el siguiente testimonio, que describe los "arreglos" estéticos a los que quedó sometida una de las integrantes de la comunidad polaca antes de presentarse como candidata en las elecciones de la reina, durante la Fiesta Nacional del Inmigrante de Oberá:

Y acá hay como una media locurita así digamos dentro de la colectividad con la gente mayor, que tiene que ser rubia la persona más o menos... Yo no sé si vos te fijaste, pero Natalia tiene el pelo bastante oscuro... Bueno, ella, cuando fue reina, la empezaron a teñir, a teñir, a teñir. Tenía que ser rubia. Y ¿por qué? Si nosotros los polacos no somos todos rubios... Pero en realidad, la mayoría de los polacos, como también alemanes, tiene el cabello más oscuro. Y acá tienen esta idea... (mujer, Oberá, 51 años, bisabuelos paternos polacos).

Como se ha señalado, las actividades que giran en torno a la presentación de trajes regionales y a la exhibición de bailes populares suelen estar acompañadas por una oferta de comida "típica" elaborada por los miembros de las respectivas colectividades y que el público puede consumir mientras aprecia el espectáculo. De esta forma, la degustación culinaria se convierte en un atractivo fundamental de la expresión de la etnicidad en el espacio público (Medina, 2003). Así como los elementos basados en el folklore polaco, la preparación de los platos "típicos" -al convertirse en un "producto" que se exhibe- está sujeta a una serie de transformaciones. También en este caso, se trata de los cambios que están fuertemente subordinados al objetivo principal que moldea dichos eventos; es decir, resultar atractivos a los espectadores participantes. En caso contrario, si no se cumple con este requisito, algunos platos o determinados ingredientes quedan eliminados del menú que se ofrece. Lo podemos observar en el siguiente testimonio:

Y después teníamos el guiso de repollo, bigos, me encanta a mí (...). Eso nosotros hicimos una vez para la fiesta esta que hacemos una vez por año, pero la gente no está acostumbrada, ¿viste? Nosotros teníamos que estar tapando el repollo, porque cuando abríamos la gente decía ‘¿qué es esto?’ Y no lo hicimos más. (mujer, colonia Wanda, 70 años, ambos padres polacos).

La especificidad de los eventos, la gran afluencia de los comensales, la necesidad de ofrecerles un plato "típico" sin que su preparación implique una espera excesiva también influyen en la elección y (re)elaboración de la oferta culinaria. Un buen ejemplo de este fenómeno lo constituye el llamado "pollo a la polonesa". Se trata de un plato que, si bien se desconoce en Polonia, durante años ha gozado de una gran popularidad durante la Fiesta Nacional del Inmigrante de Oberá. Resulta interesante la descripción del proceso de elaboración del plato y la explicación de cuáles fueron los criterios de elección de los ingredientes utilizados que nos ha ofrecido una de las integrantes de la colectividad: 


\begin{abstract}
El 'pollo a la polonesa' es un pollo asado con una salsa que es con cebollita verde, ajo, puerro y tiene champiñones y crema de leche (...). Fue una cuestión interna para vender el plato típico y habían dicho: ‘bueno, hacemos un pollo’, pero ‘¿qué le podemos poner al pollo?'. 'Y bueno, podríamos hacerlo con salsa'. 'Y ¿si hacemos la salsa así con crema?’ ‘¿Y cómo se va a llamar?’ ‘¡Pollo a la polonesa!' Y años después mi abuelo dijo que hay que agregarle champiñones. Y este es el famoso 'pollo a la polonesa'. Y es un plato que a todos les gustó. (mujer, Oberá, 27 años, bisabuelos maternos polacos).
\end{abstract}

Como se desprende del relato, la preparación del "pollo a la polonesa" ilustra, al mismo tiempo, los esfuerzos por responder a los gustos de los comensales y la preocupación que el plato tenga un claro "toque étnico". La cantidad de raciones que se venden durante el evento requiere, además, que puedan ser elaboradas fácilmente y que se adecuen al presupuesto de los que acuden a los eventos. Como resultado, el plato que durante la Fiesta Nacional del Inmigrante pretende ser representativo para la tradición culinaria polaca es un claro invento llevado a cabo por los integrantes de la colectividad. Independientemente de las estrategias empleadas a la hora de elaborar el "plato típico", lo que probablemente llame más la atención es el hecho de que, en numerosas ocasiones, los propios integrantes de la colectividad han mencionado tanto la preparación como el consumo del "pollo a la polonesa", como una forma de mantener su vinculación con el país de sus antepasados. Por lo tanto, y basándonos en las aportaciones de Gilberto Giménez, el fenómeno observado demuestra una exitosa "fabricación de autenticidad" (Giménez, 2009, p. 19).

\title{
Valor instrumental de la etnicidad
}

Por último, cabe destacar que los integrantes de la comunidad polaca, al igual que los de otras comunidades de origen inmigrante, no han permanecido pasivos ante el contexto y las circunstancias que los rodean. Por el contrario, han demostrado una capacidad para aprovechar las actuales iniciativas de visibilización de la diversidad étnica para poder beneficiarse de ellas a nivel colectivo (Cohen, 1981). Gracias al interés que despiertan entre los espectadores, las celebraciones abiertas al público se han convertido en una de las principales fuentes de ingreso para los distintos colectivos participantes (Porada, 2016). Los elementos étnicos que se exhiben -principalmente platos y bebidas "típicas", pero también distintos suvenires con motivos folklóricos- están pensados y elaborados con el objetivo de ser vendidos. Con estas palabras, una de las personas entrevistadas explica la importancia del aspecto económico:

\footnotetext{
La fiesta no es solo como el motor de difusión de la colectividad, sino también es importante por cuestión económica, porque todos ganamos plata, que luego la usamos para reinvertirla. Por ejemplo, el ballet por lo menos, después la invierte en trajes y en acondicionamiento de la sala de ensayos, en el vestuario y demás. (mujer, Oberá, 27 años, bisabuelos maternos polacos).
}

El dinero reunido durante las celebraciones queda destinado para cubrir los gastos de las respectivas entidades y, por tanto, del éxito comercial de los eventos dependen las futuras actividades desarrolladas por un determinado grupo. Es por ello que el beneficio económico de estos eventos, muchas veces, resulta fundamental para el funcionamiento de la colectividad. Es posible apreciar la preocupación por el aspecto económico en el testimonio referente a los preparativos que preceden la Fiesta Nacional del Inmigrante de Oberá: 
Lo que pasa por allí para la Fiesta del Inmigrante la gente viene a comer y le gusta la comida acá, pero ponele un 'pollo a la polonesa', que en definitiva, el pollo la gente ya come, ¿entendés? El plato típico que tiene de todo un poco (...). Pero implementar la sopa, ¿y si la gente no come y no come? Y no vienen dos o tres polacos, ¿qué hacés con esta comida? Es como una inversión para la colectividad, una inversión perdida. Entonces es un riesgo, porque las comidas que son un poco raras para el resto de la gente no se venden. Y entonces estamos viendo, a ver qué se podría hacer este año, que por lo menos una comida cambiara. Pero cuesta tanto porque sí, ponele, esas comidas, por ejemplo, la sopa que tiene remolacha (...). La gente no quiere comer eso. (mujer, Oberá, 51 años, bisabuelos paternos polacos)

En los nuevos espacios de interacción entre los distintos colectivos de origen inmigrante y la sociedad mayoritaria, la etnicidad que se expone está sujeta al riguroso cálculo de coste-beneficio. Se trata, pues, de explotar el propio pasado inmigratorio como una estrategia para autofinanciarse, e incluso emprender nuevas iniciativas que requieran de un importante respaldo económico. En este sentido, en el contexto de la escenificación, el hecho de resaltar algunos elementos que conforman la etnicidad del grupo se nos presenta como un recurso al que los individuos acuden y al que utilizan de manera intencional para obtener determinados fines (Bazurco Osorio, 2006).

\section{Conclusiones}

Los proyectos oficiales promovidos desde fuera de la comunidad polaca y dentro del marco de las políticas culturales destinadas a promocionar la imagen de Argentina como un país étnica y culturalmente diverso han repercutido en el contenido étnico que mantienen los descendientes de inmigrantes en la provincia de Misiones. La visibilización de la diversidad étnica, expresada a través de numerosas ferias, festivales y desfiles, de entrada libre y gratuita, ha ido ganando popularidad en el nordeste argentino y ha moldeado significativamente la vinculación que los integrantes del grupo conservan con la cultura de sus antepasados. La participación de los espectadores que no pertenecen a la comunidad en las actividades desarrolladas por esta ha supuesto un intenso proceso de adecuación del contenido que se exhibe. De ahí, los elementos presentados han pasado por una serie de modificaciones, que van más allá de las que se originan por el tiempo transcurrido o por el contacto permanente con la sociedad receptora y con los demás grupos étnicos. El objetivo de cumplir con las expectativas del público concurrente ha determinado, en gran medida, la forma de los símbolos que se presentan. Entre los cambios registrados, se destaca la eliminación de aquellos elementos que podrían resultar inentendibles para los espectadores, como lo es, por ejemplo, el uso de la lengua étnica, o la invención de "platos típicos". A pesar de que los elementos en torno a los que los descendientes de inmigrantes polacos construyen su sentido de pertenencia sean muy diferentes de los empleados por los propios inmigrantes o por los polacos residentes en Polonia, y aunque la actual comunidad polaca en Argentina haya adoptado los rasgos culturales de la sociedad dominante -como es su lengua-, esto no impide que continúe percibiéndose, al tiempo que sea percibida por los demás, como un grupo diferenciable.

Por otro lado, la mayor visibilidad de las comunidades de origen inmigrante en el espacio público ha influido también en el cambio de las prioridades organizativas de los respectivos centros. Estos han empezado a otorgar un lugar privilegiado a las nuevas modalidades de representación que, a su vez, han quedado asumidas como fundamentales para expresar la pertenecía étnica y 
han llegado a ocupar un lugar central en la agenda de la colectividad. La popularidad de la que gozan las nuevas iniciativas ha sido potenciada por el hecho de que estas constituyen una importante fuente de ingreso para los distintos colectivos de origen polaco. La participación en los actos abiertos al público extracomunitario, además de mostrar abiertamente su pertenencia étnica, ha permitido que los distintos colectivos se beneficiaran económicamente.

Por último, a pesar de su carácter dinámico, selectivo, altamente contextual $y$, en ocasiones, no exento de un trasfondo utilitario, los marcadores étnicos que mantienen los descendientes de inmigrantes polacos para afirmarse como integrantes de un determinado grupo son percibidos como fijos e inmunes a los cambios que ha experimentado, a lo largo de las décadas, la comunidad polaca en Argentina. Los descendientes de inmigrantes polacos se ven a sí mismos como portadores de una "verdadera cultura polaca". El uso frecuente de los adjetivos como "tradicional", "típico" o "auténtico" para referirse a los elementos seleccionados como representativos de la "polaquidad" es lo que demuestra la percepción primordialista desde la cual las personas entrevistadas elaboran su etnicidad. Consecuentemente, los cambios y transformaciones efectuadas quedan encubiertas por el aparente carácter estático de la cultura y tradiciones polacas que, según los descendientes, se transmiten sin variación de generación en generación.

\section{Financiamiento}

Este artículo se inserta en el marco del proyecto de investigación HAR2015-63689-R, financiado por el Plan Nacional de I+D+i del Ministerio de Economía y Competitividad de España. 


\section{Q Referencias bibliográficas}

" Alba, R. (1990). Ethnic Identity: The Transformation of White America. New Haven: Yale University Press.

» Barth, F. (1976). Introducción. En F. Barth (Coord.), Los grupos étnicos y sus fronteras. La organización social de las diferencias culturales (pp. 9-49). México DF: Fondo de Cultura Económica.

» Bazurco Osorio, M. (2006). Yo soy más indio que tú. Resinificando la etnicidad. Quito: Abya-Yala.

» Bialogorski, M. (2011). Performance e identidad: nuevas formas de coreaneidad en la sociedad argentina actual. Ponencia presentada durante $X$ Congreso Argentino de Antropología Social, Buenos Aires, 29 de noviembre al o2 de diciembre de 2011.

»Bro ek, A. (1984). Polityka imigracyjna w pa stwach docelowych emigracji polskiej (1850-1939). En A. Pilch (Coord.), Emigracja z ziem polskich w czasach nowo ytnych i współczesnych (pp. 141-195). Varsovia: Pa stwowe Wydawnictwo Naukowe.

"Bryszewska, M., Gmitruk, J. y Mazurek, J. (2004). Polonia Argenty ska W pi miennictwie Polskim: Antología. Varsovia: Muzeum Historii Polskiego Ruchu Ludowego.

" Cohen, A. (1981). Variables in ethnicity. En C. Keyes (Ed.), Ethnic change (pp. 306-331). Seattle: University of Washington Press.

"De la Fuente, Diego G.; Gabriel Carrasco y Alberto B. Martínez (dirs.) (1898), Segundo censo de la República Argentina. Mayo 10 de 1895. Buenos Aires: Taller Tipográfico de la Penitenciaría Nacional.

»Devoto, F. (2009). Historia de la inmigración en la Argentina. Buenos Aires: Sudamericana.

" Fischman, F. (2011). Para nosotros y para los otros. Celebraciones y conmemoraciones públicas judías argentinas. Ponencia presentada durante X Congreso Argentino de Antropología Social, Buenos Aires, 29 de noviembre al o2 de diciembre de 2011.

" Fischman, F. (2013). Expresiones artísticas multifacéticas en las calles de Buenos Aires: la identidad judía argentina entre el klezmer, el tango y el stand up. Karpa, 6, 1-14. Recuperado de http://www.calstatela.edu/al/karpa/karpa-6

» Gans, H. (1979). Symbolic ethnicity: The future of ethnic groups and cultures in America. Ethnic and Racial Studies, 2(1), 1-20.

» Geertz, C. (1992). La interpretación de las culturas. Barcelona: Gedisa.

» Gil, G. J. (2007). Las identidades regionales italianas en la Argentina y la reinvención de la etnicidad. Estudios Migratorios Latinoamericanos, 63, 299-330.

" Giménez, G. (1997). Materiales para una teoría de las identidades sociales. Frontera Norte, 9(18), 9-28.

» Giménez, G. (2009). Cultura, identidad y memoria. Materiales para una sociología de los procesos culturales en las franjas fronterizas. Frontera Norte, 21(41), 7-32.

"Grimson, A. (2006). Nuevas xenofobias, nuevas políticas étnicas en Argentina. En A. Grimson y E. Jelin (Comp.), Migraciones regionales hacia la Argentina. Diferencia, desigualdad y derechos (pp. 69-97). Buenos Aires: Prometeo.

»Guber, R. (1995). De la etnía a la nación. Cuadernos de Antropología Social, 8, 61-80. 
》 Guber, R. (2001). La etnografía, método, campo y reflexividad. Bogotá: Norma.

» Handler, R. (1986). Authenticity. Anthropology Today, 2(1), 2-4.

» Irazuzta, I. (2001a). Argentina: una construcción ritual: nación, identidad y clasificación simbólica en las sociedades contemporáneas. Bilbao: Universidad del País Vasco.

" Irazuzta, I. (2001b). La sociedad en los bordes. Una representación ritual de la construcción/ deconstrucción de fronteras sociales. Política y Sociedad, 36, 39-53.

» Kantor, R. (1990). Folklor grupy emigruj cej. Etnograficzne wprowadzenie do zagadnienia miejsca i roli folkloru w kulturze zbiorowo ci polonijnych. En R. Kantor, J. Rokicki (Comp.), Oj zyk i kultur polsk w rodowiskach polonijnych (pp. 31-37). Varsovia: Biblioteka Narodowa.

» Kraustolf, E. (2011). Kolonizacja prywatna w Misiones: Kolonie Wanda i Lanusse, 1936-1960. Relacje zebrane w latach 2005-2007. En R. Stemplowski (Coord.), Polacy, Rusini i Ukrai cy, Argenty czycy Osadnictwo w Misiones 1892-2009 (pp. 471-512). Varsovia: Muzeum Historii Polskiego Ruchu Ludowego e Instytut Studiów Iberyjskich i Iberoameryka skich UW.

» Martí, J. (1996). El folklorismo. El uso y abuso de la tradición. Barcelona: Ronsel.

» Martí, J. (1999). La tradición evocada: folklore y folklorismo. En Tradición Oral (pp. 81107). Santander: Universidad de Cantabria.

» Martínez, A. B. (1916), Tercer censo nacional de 1914. Buenos Aires: Talleres Gráficos de L. J. Rosso.

» Mazurek, J. (2006). Kraj a emigracja. Ruch lodowy wobec wychod stwa chłopskiego do krajów Ameryki Łaci skiej (do 1939 roku). Varsovia: Instytut Studiów Iberyjskich i Iberoameryka skich Uniwersytetu Warszawskiego i Muzeum Historii Polskiego Ruchu Ludowego w Warszawie.

» Medina, F. X. (2003). Ciudad, etnicidad y alimentación. Restaurantes, tabernas y la construcción de territorios de identidad vascos en Barcelona. Zainak, 24, 835-846.

» Monkevicius, P. (2010). Memoria social y producción de relatos orales en las asociaciones étnicas lituanas. Avá, 18, 61-74.

»Parma, S. (2013). El patrimonio cultural inmigratorio y su uso como recurso turístico. Caso: ciudad de Berisso. Tesis de licenciatura presentada en la Facultad de Ciencias Económicas, Universidad Nacional de la Plata (Argentina).

» Pizarro, C. (2013). La bolivianidad en disputa. (Des)marcaciones de etnicidad en contextos migratorios. En G. Karasik (coord.), Migraciones internacionales. Reflexiones y estudios sobre la movilidad territorial contemporánea (pp. 331-36o). Buenos Aires: Ciccus.

»Porada, K. (2016). Procesos de formación de la identidad étnica de un grupo de origen inmigrante en Argentina. Los descendientes de polacos en Buenos Aires y Misiones. Madrid: Polifemo.

»Quijada, M. (1992). De Perón a Alberdi: selectividad étnica y construcción nacional en la política inmigratoria argentina. Revista de Indias, LII (195-196), 867-888.

»Segato, R. (2007). La nación y sus otros. Raza, etnicidad y diversidad religiosa en tiempos de políticas de la identidad. Buenos Aires: Prometeo.

»Smolana, K. (1983). Za ocean po lepsze zycie. En M. Kula (coord.), Dzieje Polonii w Ameryce Łaci skiej (pp. 39-6o). Wroclaw: Ossolineum.

»Stemplowski, R. (2011). Polacy, Rusini i Ukrai cy, Argenty czycy Osadnictwo w Misiones 1892-2009. Varsovia: Muzeum Historii Polskiego Ruchu Ludowego e Instytut Studiów lberyjskich i lberoameryka skich UW. 
» Trebunia-Staszel, S. (2014). Kultura ludowa nieutracona. Współczesne oblicza regionalnej kultury Podhala. En B. Fatyga y R. Michalski (Eds.), Kultura ludowa. Teorie - praktyki - polityki (pp. 251-287). Varsovia: Instytut Stosowanych Nauk Społecznych.

»Waters, M. (1990). Ethnic Options: Choosing Identities in America. Los Ángeles: University of California Press. 